\title{
A Service Science Perspective on Resilience of Service Organisations
}

\author{
Thang Le Dinh ${ }^{1, *}$, Thanh Thoa Pham Thi ${ }^{2}$, Nguyen Anh Khoa Dam ${ }^{1}$, and William Menvielle ${ }^{1}$ \\ ${ }^{1}$ Business School, Université du Québec à Trois-Rivières, C.P 500, Trois-Rivières, Québec, G9A5H7, \\ Canada \\ ${ }^{2}$ College of Business, Technological University Dublin, Dublin, Ireland
}

\begin{abstract}
Nowadays, different types of unexpected turbulence and disruptions lead to challenges and changing conditions of the environment that organisations operate. The previous studies related to crisis response or service recovery have addressed many aspects of the governance of an organisation in reacting to crisis or failure situations, including innovation and bureaucracy, science and politics, and decision-making speed. However, there is still little attention on supporting service organisations to revise and adapt their business services in a coherent manner to overcome the challenges from disruptive events. In order to improve organisational resilience, this paper presents an approach based on the service science perspective for service organisations to adapt their services at the three levels of service science, including the network of service systems, service system, and service levels. The paper also presents a case study of using the proposed approach in cultural organisations and ends with a discussion and some conclusions.
\end{abstract}

\section{Introduction}

Nowadays, organisations have to deal with rapid changing conditions of the business environment caused by different types of unexpected turbulence and disruptions [1]. Crisis response and service recovery address the governance of an organisation in reacting to crisis or failure situations, which generally focuses on certain specific aspects such as innovation and bureaucracy, science and politics, and decision-making speed [2,3]. Crisis response itself can be considered as a complex system with fuzzy boundaries and different actors from various parts of organisations and serve one or more crisis response tasks [2]. On the other hand, service recovery involves actions resolving problems related to the negative attitudes of dissatisfied consumers [3].

Concerning service organisations, the competitive environment poses new threats and challenges to those organisations due to the increased turbulence in markets, industries as well as natural and social disasters [4]. One of the answers to those challenges is to design an organisational system that aims at enhancing organisational resilience $[2,3,4]$. However, there is still little attention on revising and adapting the organisational system in a coherent manner

\footnotetext{
${ }^{*}$ Corresponding author: thang.ledinh@uqtr.ca
} 
and at all levels of service science, which are the network of service systems, the service system, and the service levels [5].

For this reason, this paper presents a conceptual framework based on the service science perspective for service organisations to adapt their business services at the three such levels in order to enhance the organisational resilience. The rest of the paper is structured as follows. First, the background and principles of organisational resilience are presented. Then, the framework for service organisations to enhance organisational resilience is explained. A case study of using the proposed framework in cultural organisations is also presented, followed by the discussion, some conclusions, and suggestions for future research.

\section{Theoretical background}

This section provides the definition and characteristics of different aspects of organisational resilience and service science that serve as the background for this research.

\section{Organisational resilience}

Resilience originates from the English verb "resile" which means "to return to a former state or original position" [6]. Accordingly, organisational resilience is the ability to recover from and adjust to unprecedented disruptions such as epidemics and pandemics $[2,3,6]$.

To put it another way, organisational resilience covers two perspectives: i) to recover from adverse circumstances, and ii) to develop new capabilities to thrive from unexpected challenges [6]. The first perspective of organisational resilience focuses on the coping capability for the development and implementation of effective solutions dealing with adverse situations [7]. On the flip side, the second perspective of organisational resilience spotlights the adaptive capability to capitalize on unexpected changes [8]. From this point of view, enterprises view disruptions as a positive and opportunistic aspect to build a successful future [9].

\section{Organisational system}

An organisational system consists of a complex network of interrelated elements and subsystems, which are composed of both social and technical components that interact through nonlinear relationships to form an organisation's unique identity [1]. This system needs to be changed and adapted in response to environmental turbulence, which threatens both the operation and survival of an organisation, in order to sustain function and retain advantage [1].

Consequently, organisations have to deal with the implications of discontinuities and disruptions due to turbulence within their operating environments [1, 2]. They need to develop different capacities of resilience to face those challenges [10]. Related to service organisations, there are two important capacities: i) Ability of an organisation to strengthen the creation of robust and flexible processes in a proactive way, and ii) Ability to anticipate key events towards emerging trends, to adapt constantly to change and to recover quickly after disasters and crises.

\section{Organisational system based on service science perspective}

Based on the service science perspective, a service organisation should be comprised of three dimensions: science, management, and engineering [5]. The management dimension of an organisation concerns the service proposal, which aims at carrying out business strategies to create value from its business services [5]. The science dimension concerns the service creation, 


\section{IESS 2.1}

which deals with the structure of the service system of the organisation to apply its competencies for the benefit of customers [5]. The engineering dimension concerns the service operation, which covers the invention of new technologies to improve the quality of business services [5].

Consequently, the organisational system of a service organisation includes three levels: the network of service systems for service proposal, the service system for service creation, and the service levels for service operation [11].

The network of service systems level, corresponding to the service proposal, aims at modelling business services as a chain of value creation and exchange in which service systems coproduce common results [11]. The network of service systems is reconceptualized from the traditional supply chain, also called the service value creation network that is a group of economic entities working together to achieve not only their own goals, but also a collective goal $[12,13]$.

The service system level, corresponding to the service creation, involves the configuration and implementation of business services in a service system to ensure adequate resources and sufficient technological support for services [11]. A service system functions as a "valuecoproduction configuration of people, technology, other internal and external service systems, and shared information" through the support of different resources [14].

The service level, corresponding to the service operation, emphasizes the operational aspects of a business service, especially what is provided to customers and how it is provided [11]. A business service is the use of an economic entity's specific competencies, such as knowledge, skills and technologies, for the benefit of another economic entity [15].

\section{A Framework for Organisational Resilience Enhancement}

This part of the study presents the framework for organisational resilience enhancements, hereafter called the ORE framework. Set the foundation upon design science, the ORE framework includes research artefact such as constructs, models, methods, and instantiations [16]. The ORE framework is indeed an enhanced framework from our previous work [5, 11] that is adapted to the organisational resilience enhancement context.

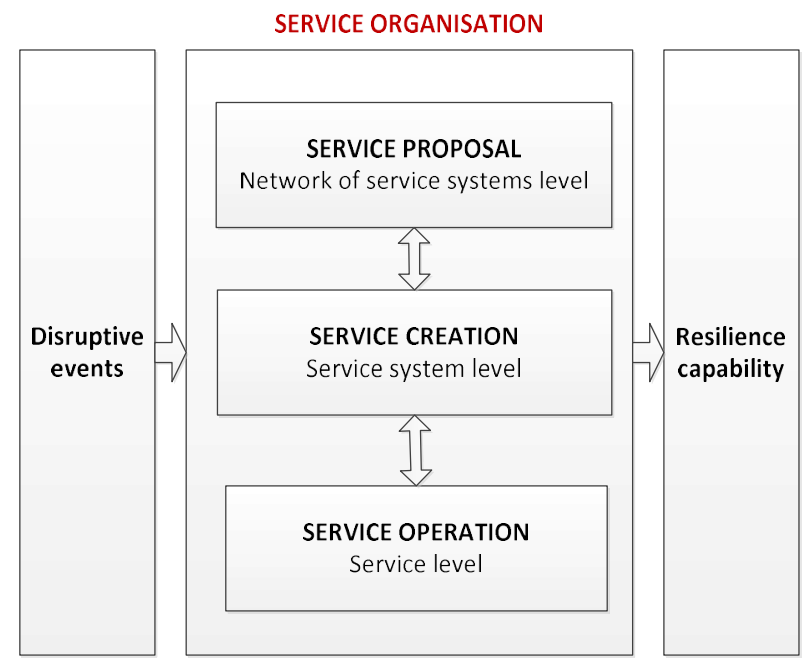

Fig. 1 Framework for organisational resilience enhancement. 
As presented in Figure 1, the ORE framework aims at enhancing organisational resilience by developing resilience capability to overcome the challenges of disruptive events, including the three levels of service science: the network of service systems, service system, and service levels.

\subsection{Constructs of the ORE framework}

Constructs of the ORE framework form the key concepts of domain knowledge that constitute a conceptualization to describe the disruptions within the business ecosystem and to specify the solutions [16]. In the service science perspective, there are three key constructs corresponding to the three levels of service systems: Network, Service system, and Service (Table 1).

Table 1. Constructs of the ORE framework.

\begin{tabular}{|c|c|c|c|c|}
\hline Level & Objective & $\begin{array}{c}\text { Key } \\
\text { construct }\end{array}$ & Relevant constructs & $\begin{array}{c}\text { Resilience-related } \\
\text { constructs }\end{array}$ \\
\hline $\begin{array}{c}\text { Network of } \\
\text { service } \\
\text { systems }\end{array}$ & $\begin{array}{c}\text { Service } \\
\text { proposal }\end{array}$ & Network & $\begin{array}{c}\text { Economic entity, Value } \\
\text { proposal }\end{array}$ & $\begin{array}{c}\text { Event, Disruptive } \\
\text { event, Threat, } \\
\text { Detection }\end{array}$ \\
\hline $\begin{array}{c}\text { Service } \\
\text { system }\end{array}$ & $\begin{array}{c}\text { Service } \\
\text { creation }\end{array}$ & $\begin{array}{c}\text { Service } \\
\text { system }\end{array}$ & Infrastructure, Resources & Activation \\
\hline Service & $\begin{array}{c}\text { Service } \\
\text { operation }\end{array}$ & $\begin{array}{c}\text { Business } \\
\text { service }\end{array}$ & $\begin{array}{c}\text { Business object, Business } \\
\text { Activity, Business rule, } \\
\text { Dynamic state }\end{array}$ & Response \\
\hline
\end{tabular}

At the network of service systems level, there are the following constructs: Network, Economic entity, Value proposal, Event, Disruptive event, and Detection. A network is a group of economic entities working together to achieve not only their own goals, but also a collective goal [5]. An economic entity could be an individual, an enterprise, a government, or an economy [11]. In the context of resilience, economic entities could be customers, suppliers, business partners, government agencies, and financial institutes [11]. A value proposal is a value produced by transferring things or by improving some states of service clients [11]. An event is something that may happen in a network. A disruptive event is an unexpected event or a major disruption that threatens the process of value creation of an organisation [1]. A threat (or a disruption) can have a direct effect on an organisation's ability to provide services to customers. A detection is an activity that strengthens the ability of the organisation to recognize potential threats [1].

At the service system level, there are the constructs such as Service system, Infrastructure, Resource, and Activation. A service system is a configuration of resources and infrastructure to promote the value coproduction process [13]. Infrastructure includes relevant resources that are used by a service system and are shared with other service systems. Infrastructure can be subdivided into human infrastructure, informational infrastructure, and technical infrastructure, all of which can be essential to a service system's operation [17]. Correspondingly, resources are required for creating value, called resourcing, that is performed by a service system [12]. There are different types of resources such as human, informational, and technical resources [17]. Concerning resilience-related activities, an activation is an activity that begins to deploy the available resources within the organisational system to elicit an adjustment to a disruption.

At the service level, there is Business service, as the key construct of this level and its relevant constructs such as Business object, Business activity, Business rule, Dynamic state, and Response. A business service is a result of the collaboration between different economic entities 


\section{IESS 2.1}

in a network in order to achieve a collective goal [11]. A business object is an actor within the business layer that represents a part of an organisation that has its own goal and a set of interrelated information and knowledge to support business services [11]. A dynamic state of a business object is a situation during which certain business activities are "enabled" and others "disabled" [11], and the enabled business activities transform the business object from that state to another dynamic state, which is different from a static state where the state of business objects is not changed. A business activity is a response from the service system to the occurrence of an event provoked by an economic entity that may transit from a dynamic state to another dynamic state of a business object [11]. A business rule is a set of constraints on how the business activities must operate [11]. Finally, a response is an activity that enables resilience capability to respond quickly and effectively to disruptions [1].

Table 2 presents typical disruptive events and relevant constructs extracted from an organisational resilience reference framework [10].

Table 2. Typical disruptive events and related constructs.

\begin{tabular}{|c|c|c|c|}
\hline $\begin{array}{c}\text { Economic } \\
\text { entity }\end{array}$ & Disruptive event & Threat & Response \\
\hline Customer & $\begin{array}{l}\text { Unpredictable changes } \\
\text { in demand }\end{array}$ & $\begin{array}{l}\text { Damage to } \\
\text { reputation/brand }\end{array}$ & $\begin{array}{l}\text { Search for additional production } \\
\text { capacity }\end{array}$ \\
\hline Organisation & $\begin{array}{l}\text { Breakdown/failure of } \\
\text { machines and/or } \\
\text { key equipment }\end{array}$ & Business interruption & $\begin{array}{c}\text { Definition of alternative routes } \\
\text { and flexible equipment } \\
\text { purchases }\end{array}$ \\
\hline Energy supplier & $\begin{array}{l}\text { Interruption in the } \\
\text { supply of water, } \\
\text { gas, electricity, etc. }\end{array}$ & $\begin{array}{l}\text { Delays in and failed } \\
\text { due dates }\end{array}$ & $\begin{array}{c}\text { Definition and implementation } \\
\text { of formal protocols to proceed } \\
\text { when supply interruptions } \\
\text { occur }\end{array}$ \\
\hline $\begin{array}{c}\text { Financial } \\
\text { partner }\end{array}$ & $\begin{array}{l}\text { Restricted access } \\
\text { to credit }\end{array}$ & $\begin{array}{l}\text { Impossibility to pay } \\
\text { personnel, suppliers, } \\
\text { taxes }\end{array}$ & $\begin{array}{c}\text { Create a reserve fund and define } \\
\text { policies that maintain a } \\
\text { percentage of the monetary } \\
\text { reserve }\end{array}$ \\
\hline $\begin{array}{c}\text { Government } \\
\text { agency }\end{array}$ & $\begin{array}{c}\text { Changes in } \\
\text { legislation } \\
\text { involving } \\
\text { organisation's } \\
\text { products/services }\end{array}$ & Business interruption & $\begin{array}{c}\text { Train organisation's employees } \\
\text { in legal issues }\end{array}$ \\
\hline Organisation & $\begin{array}{l}\text { Key personnel } \\
\text { leaving the } \\
\text { enterprise }\end{array}$ & $\begin{array}{l}\text { Failure to attract or } \\
\text { retain top talent }\end{array}$ & $\begin{array}{l}\text { Implementation of emphasis } \\
\text { policies for recruiting and } \\
\text { retaining outstanding employees }\end{array}$ \\
\hline Supplier & $\begin{array}{l}\text { Poor quality of the } \\
\text { raw materials or } \\
\text { components } \\
\text { supplied }\end{array}$ & $\begin{array}{l}\text { Failure to meet } \\
\text { customer needs }\end{array}$ & Search for alternative suppliers \\
\hline
\end{tabular}

Concerning the Detection and Activation constructs, the general descriptions are as the following [10]: i) Detection registration: Disruption ID, Name, Date, Time, Description, Functional areas, Resource involved, Causes identified, Legislative / regulatory aspects, and Consequences.; and ii) Activation registration: Recovery action ID, Description, Steps, Resource required, Responsible, Time, and Duration. 


\subsection{Model of the ORE framework}

The model of the ORE framework is a set of statements expressing the relationships between the constructs [16]. In this paper, those relationships are represented based on the simplified UML notation [18] as in Figure 2. Each class represents a construct. There are different relationships between classes such as specialisation (B is a kind of A), dependency (B needs A) and composition (B is a part of $\mathrm{A}$ ) [18].

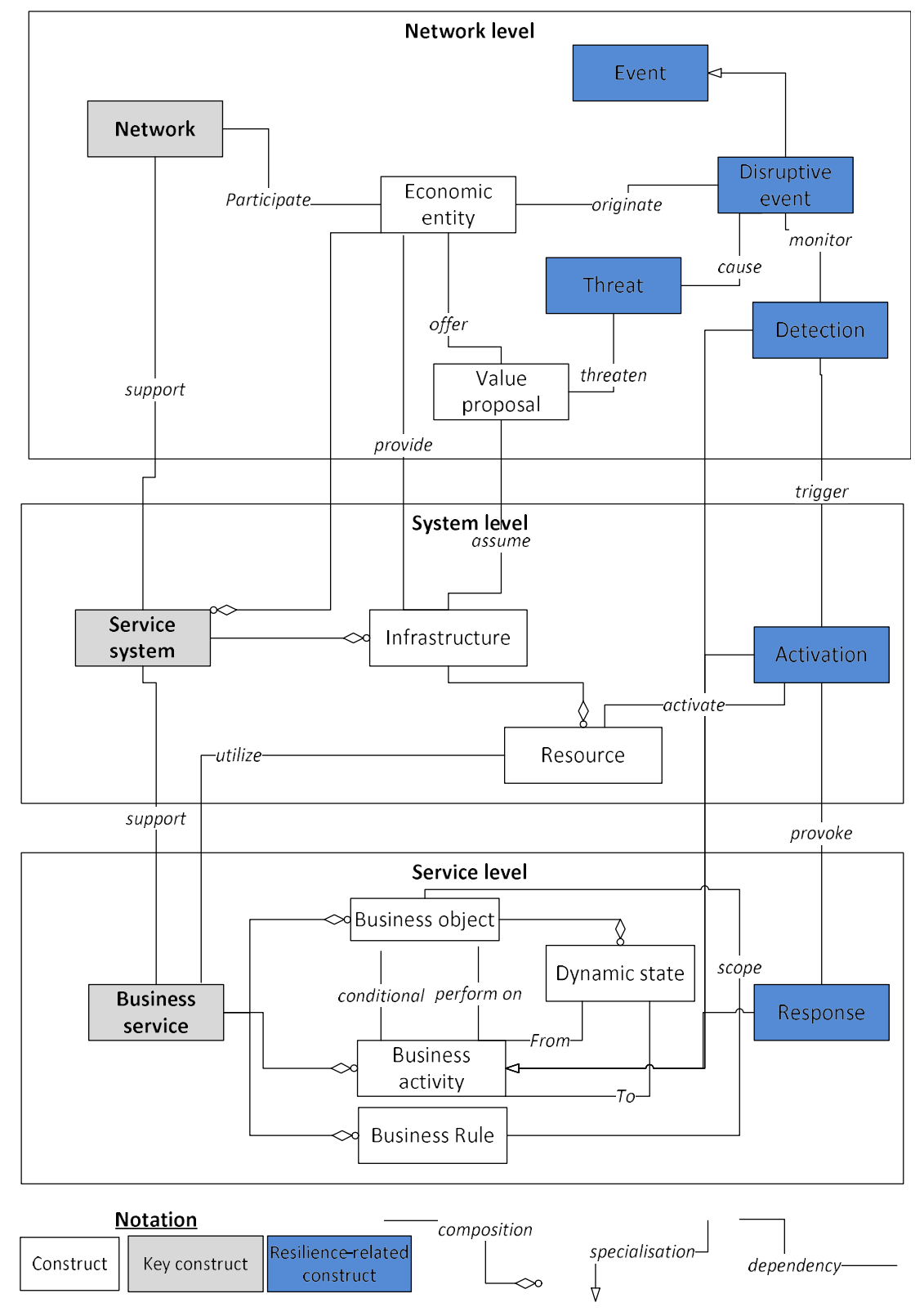

Fig. 2. The Model of the ORE framework. 


\section{IESS 2.1}

Concerning the network of service systems level, different economic entities participate in a network. Each economic entity may offer one or several value proposals. A disruptive event is a special type of events that may lead to threats. A detection is an activity that monitors disruptive events.

Concerning the service system level, an economic entity consists of one or several service systems with different infrastructure. Each infrastructure operates with a set of resources. A detection activity may trigger the corresponding activation activity to prepare resilience responses. The activation activity may activate the required resources.

Concerning the service level, a business service receives supports from a service system. A business service is comprised of a set of business objects, a set of business activities that operate on those business objects, a set of business rules for conducting those business activities. A business object may have various dynamic states. A business activity may change the dynamic states of a business object. An activation activity may provoke a response activity to respond to a disruption in order to survive and prosper.

\subsection{Method of the ORE framework}

The method, which is a set of steps for solution development, demonstrates relationships among constructs [16]. This paper applies an extension of the Petri-net [19] to present the method of the ORE framework towards the dynamic and static aspects of business objects supporting a resilience situation [20]. As presented in Figure 3, the method outlines the resilience process over the three levels of service systems. The method includes steps to follow and the dynamic states related to a resilience situation obtained after each step.
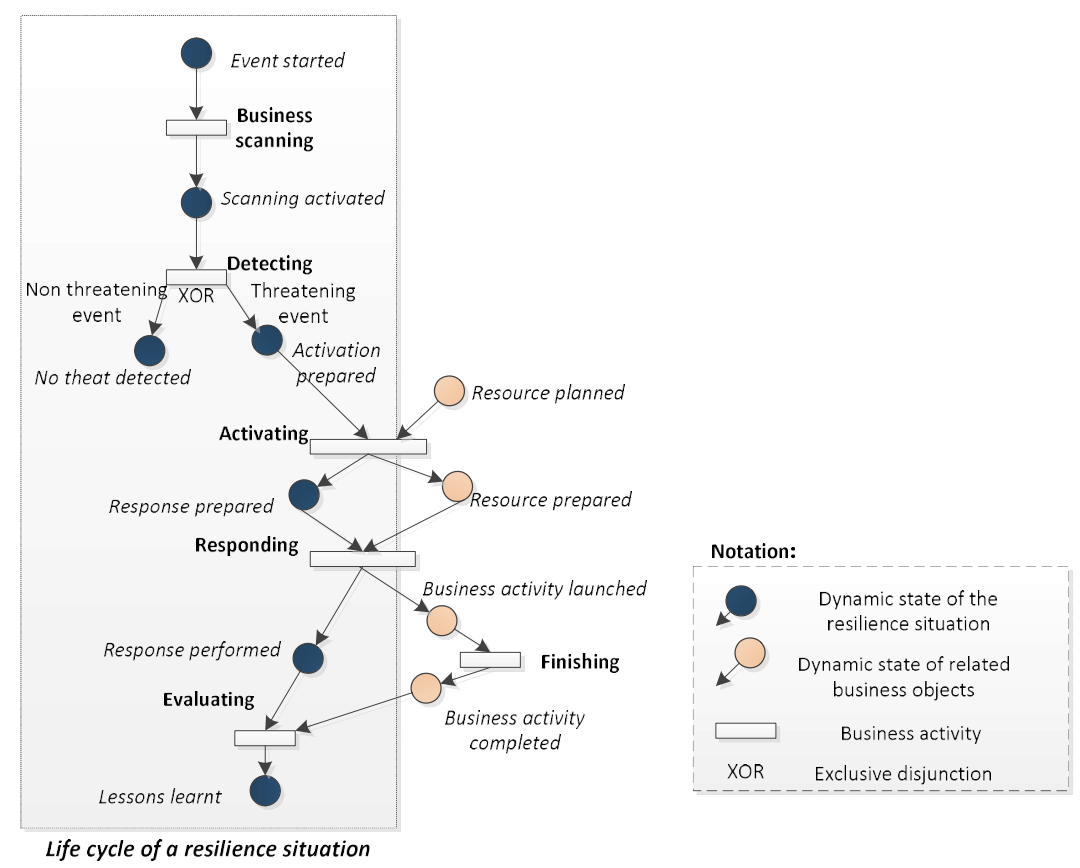

Fig. 3. Method of the ORE framework.

Table 3 presents the general business activities related to a resilience situation corresponding to a disruptive event, which can be as either an opportunity or a threat [1]. 
Table 3. Business activities related to a resilience situation.

\begin{tabular}{|c|c|c|c|}
\hline $\begin{array}{c}\text { Business } \\
\text { activity }\end{array}$ & \multicolumn{1}{|c|}{ Description } & $\begin{array}{c}\text { Previous } \\
\text { state }\end{array}$ & New state \\
\hline $\begin{array}{c}\text { Business } \\
\text { scanning }\end{array}$ & $\begin{array}{c}\text { Business scanning activity aims at assessing the } \\
\text { business environment and operating condition against } \\
\text { the occurred event. The result of this activity feeds the } \\
\text { next activity Detecting }\end{array}$ & $\begin{array}{c}\text { Event } \\
\text { started }\end{array}$ & $\begin{array}{c}\text { Scanning } \\
\text { activated }\end{array}$ \\
\hline Detecting & $\begin{array}{c}\text { Based on the scanning result, the Detecting activity } \\
\text { recognises the nature of the event within the business } \\
\text { environment, and then detects disruptive events and } \\
\text { threats or decides whether the event is non-threatening. } \\
\text { If the event is a threat, it moves to the } \text { Activating } \\
\text { activity. }\end{array}$ & $\begin{array}{c}\text { Scanning } \\
\text { activated }\end{array}$ & $\begin{array}{c}\text { No threat } \\
\text { detected } \\
\text { OR } \\
\text { Activation } \\
\text { prepared }\end{array}$ \\
\hline Activating & $\begin{array}{c}\text { This activity outlines the resources that the } \\
\text { organisational system need to prepare for an adjustment } \\
\text { to a disruption. }\end{array}$ & $\begin{array}{c}\text { Activation } \\
\text { prepared }\end{array}$ & $\begin{array}{c}\text { Response } \\
\text { prepared }\end{array}$ \\
\hline Responding & $\begin{array}{c}\text { This is where the adjustment happens. The adjustment } \\
\text { can involve the existing business activities or create } \\
\text { new business activities. The knowledge and } \\
\text { experiences around the responding phase are registered } \\
\text { to provide the next activity for evaluating. }\end{array}$ & $\begin{array}{c}\text { Response } \\
\text { prepared }\end{array}$ & $\begin{array}{c}\text { Response } \\
\text { performed }\end{array}$ \\
\hline $\begin{array}{c}\text { The result of the response and knowledge registered in } \\
\text { the previous step is then assessed. They help to draw } \\
\text { lessons for improving the resilience in the future. }\end{array}$ & $\begin{array}{c}\text { Response } \\
\text { performed }\end{array}$ & $\begin{array}{c}\text { Lesson } \\
\text { learnt }\end{array}$ \\
\hline
\end{tabular}

Based on the proposed method, a service organisation may develop a more specific resilience process to overcome a particular disruptive event and determine the impact on business objects. To demonstrate the application of the method, the paper presents an example of a disruptive event on "unpredictable change in demand". This event occurs due to the customer's unpredictable changes in demand such as an increase in production quantity. The Customer demand is a business object, which is in charge of this resilience situation. This disruptive event starts a specific resilience process as mentioned in Table 4.

Table 4. Example about the specific resilience process related to "unpredictable changes in demand".

\begin{tabular}{|c|c|c|}
\hline Activity & Description & $\begin{array}{c}\text { Related business } \\
\text { objects }\end{array}$ \\
\hline $\begin{array}{c}\text { Business } \\
\text { Scanning }\end{array}$ & $\begin{array}{c}\text { Review and assess the current production capacity, the } \\
\text { resources and the customer relationship }\end{array}$ & $\begin{array}{c}\text { Production, } \\
\text { Resource }\end{array}$ \\
\hline Detecting & $\begin{array}{c}\text { After getting a complete picture of the business environment, } \\
\text { an event is considered as a threat because the demand is over } \\
\text { the current production capacity and the customer is the key } \\
\text { customer }\end{array}$ & $\begin{array}{c}\text { Customer, } \\
\text { Production }\end{array}$ \\
\hline Activating & $\begin{array}{c}\text { Preparing for improving production capacity by searching } \\
\text { different solutions such as outsourcing production or } \\
\text { increasing resources }\end{array}$ & $\begin{array}{c}\text { Production, } \\
\text { Resource, } \\
\text { Supplier }\end{array}$ \\
\hline Responding & $\begin{array}{c}\text { Increasing the production capacity by outsourcing production, } \\
\text { starting the outsourcing production process }\end{array}$ & $\begin{array}{c}\text { Supplier, } \\
\text { Purchase order } \\
\text { Customer }\end{array}$ \\
\hline Evaluating & $\begin{array}{c}\text { Assess the solution in terms of benefit, cost, and reputation. } \\
\text { Purchase order, } \\
\text { Sale order }\end{array}$ \\
\hline
\end{tabular}




\section{A Case Study: Organisational Resilience for Cultural Organisations}

The instantiation of the framework is the realization of an artefact in its environment to demonstrate the feasibility and effectiveness of the proposed framework [16]. This paper validates an instantiation with a case study that demonstrates the application of the framework for improving the organisational resilience for cultural organisations in the context of the COVID-19 pandemic in Québec, Canada.

Based on the Canadian Framework for Culture Statistics [21], there are six culture domains such as Heritage and Libraries, Live Performance, Visual and Applied Arts, Written and Published Works, Audio-visual and Interactive Media, and Sound Recording. The pandemic has had a sudden and substantial impact on the live performance domain. Therefore, the paper continues with the live performance domain of the cultural sector with the focus on a particular subdomain: Performing arts [21].

The following part involves the instantiation of the important constructs of the ORE framework for improving the organisational resilience for cultural organisations.

\section{Instantiation at the Network of service systems level}

This illustrative example takes the current situation of theatres in the COVID-19 pandemic as a disruptive event. This disruptive event poses a serious threat through the limitation of the operation of Performance art, especially theatres. In particular, the social distance policy has a devastating effect on the ability of theatres to provide services to audiences. Concerning onstage shows, theatres are challenging to figure out alternative options for performances that require close contact among performers. Decreases in sales and the number of audiences are major detections that theatres can rely on to recognize threats of disruption. The value proposal of theatres is to produce, distribute, and preserve performing-arts events [22, 23].

At the network of service systems level, a network consists of different economic entities, including theatre and its related entities such as market, champions, and experts [24, 25].

Firstly, a market consists of audiences and funding organisations or sponsors [26, 27]. The role of audiences is to consume cultural products or services whereas funding organisations or sponsors provide funds to spread cultural work to the public [27, 28]. In other words, audiences receive value proposals from theatres.

Secondly, champions can be either art organisations, dealers, culture agencies, merchandisers, patrons, or collectors, whose purpose is to diffuse the work [26, 27]. The main value proposal of champions as art organisations is to increase the discoverability of cultural content $[27,29]$. Champions are also in charge of looking for experts who can manipulate consumer behaviours [30, 31].

Finally, experts include critics or specialists in specific domains for value judgment. The value proposal of experts with their "legitimate tastes", particularly skills and imagination, is to recognize and label art values for the work $[32,33]$.

\section{Instantiation at the Service system level}

For the instantiation at the service system level, theatres are perceived as service systems. Service systems operate resources and infrastructure for service creation. 
In terms of resources, theatres can take advantage of physical, human, organisational, and network resources during the pandemic. In light of physical resources, theatres can provide digital platforms to support the activation activity through virtual shows or streamlining onstage events [34, 35]. Physical infrastructure in the context of digital resilience includes equipment, software, and information technologies to develop a viable recovery strategy [36, 37]. Concerning organisational resources, theatres can adjust organisational culture, structure, communication, and policy as an activation to stimulate the digital transformation for theatres $[38,39]$. Organisational adaptations that focus on strategic activations such as digital transformation can support the sustainability of business [40]. Regarding human resources, an activation involves coordinating performers, backstage and frontline employees in an efficient manner for operation [41, 42]. Lastly, network resources highlight the importance of an activation from networks such as government agencies, associations, relief organisations, and other stakeholders to respond to disruptive events [30, 33]. Furthermore, theatres can expand their network with other sectors, especially the education sector, to receive timely assistance [44].

\section{Instantiation at the Service level}

At the service level, this example will focus on performers as business objects and performance as business service. Performers include actors, dancers, musicians, singers, and stuntmen. They perform on stage in front of audiences to creatively express their artistic talent. Due to the social distance policy, theatres as service systems have established various business activities to cope with the disruptive event. For example, a business activity dealing with the risk of dispersion of droplets in playing instruments or singing is that theatres maximize physical distancing among performers. For casting and auditions, theatres propose a business activity to cast remotely wherever possible by using virtual meetings or other digital platforms. Concerning costumes, wardrobe, hair and makeup services, theatres conduct a business activity in restricting dressing rooms to a single usage.

To conduct business activities, a set of business rules are proposed to ensure safety and minimize the risk of getting the Coronavirus. Some business rules are presented as follows:

- Each audience must keep a social distance of two meters.

- The number of attendees is subject to the provincial law on the capacity of avenues.

- Staff must conduct effective cleaning and hygiene practices between performances.

- Ensuring a minimum distance of three meters between performers and audience seating areas.

- Assigning a designated area on stages for artists to maintain physical distancing.

In the context of the COVID-19 pandemic, these business rules have a severe effect on how service systems propose business service. Many service systems have adopted different $d y n a m i c$ states of business service as a response to disruption. Accordingly, performance can be either synchronous or asynchronous. Each type of performance may have a different set of dynamic states. Synchronous performance takes advantage of digital platforms to livestream on-stage shows. Furthermore, synchrony can happen through pre-recorded shows that will be broadcast on digital platforms. On the other hand, asynchronous performance is onsite performance; whereas, asynchronous performance should be outdoor whenever possible to avoid large gatherings. 


\section{Discussion}

In this section, the paper discusses the similarities and differences between the proposed framework and related work, including Resilience response framework [1], Reference framework for Enterprise Resilience Enhancement [10], and Multilevel framework [7].

Firstly, the Resilience response framework in [1] outlines the flow of activities or constructs that represent the organisational behaviour during disruptions. The framework indicates that an event can be a threat, which leads to the Detection and Activation phase. After this phase, Response is triggered. The Response is then evaluated, if it is a Positive Adjustment then it is considered as a resilient response of organisational system. Both positive and negative adjustments feed the learning activity for monitoring within the detection and activation phase for the next events.

The constructs in [1] inspires the ORE framework, which is adapted according to the context of service organisations. The ORE framework explicitly describes two aspects of the organisational resilience: the resilience process and the business services. Therefore, in this framework, the organisational resilience steps are explored over three levels of the service systems. At each level, it shows how the activities in the resilience process relate to the business assets such as resources, business objects, business activities, and economic entities. By this way, it helps to understand better the impacts of resilience response over the business services.

Secondly, the Reference framework for Enterprise Resilience Enhancement [10] pre-selects a set of disruptive events that are considered as endangerments to the organisation continuity and proposes the corresponding preventive actions. In this framework, the preparedness capacity and the recovery capacity represent the enterprise resilience. The preparedness capacity is reflected by implementing the defined preventive actions. For unavoidable disruptive events, the focus is on mitigating the negative consequences [10], and the related knowledge is registered, which contributes to the recovery capacity.

Because this is a conceptual reference framework, it focuses more on the constructs and their relations rather than the resilience process to apply. The ORE framework refers to the same disruptive events as defined in [10], and enhanced with the resilience process over the three levels of the service systems.

Finally, the Multilevel framework [7] is another framework to enhance organisational resilience. The framework follows the proactive strategy, it focuses on testing and checking the preparedness capability of organisations based on exercises and crisis scenarios to strengthen the preparedness capability. It starts with reviewing and monitoring the context at three levels: individual resources review, organisational resources review and external environment review. The reviewing helps to understand the capability of an organisation at each level. Testing preparedness step focuses on the weaknesses identified in the previous step to check the preparedness. The responses then are analysed and assessed at each level. The analysis result is then used as lessons learnt to strengthen the capabilities.

The ORE framework follows a different reactive strategy, which is based on the service science perspective in the context of service organisations. It sets out to disruptive events that trigger the resilience process along the network level, service system level and service level.

\section{Conclusion}

Enterprises and organisations today face different types of unexpected turbulence and disruptions that change the conditions of the business environment. Consequently, there is still 
a need for a foundation for organisational resilience in service organisations. For this reason, our research focuses on proposing a framework for enhancing organisational resilience based on the service science perspective, called the Organisational Resilience Enhancement (ORE) framework. The framework consists of the three levels of service science, including the Network of service systems for service proposal, the Service system level for service creation, and the Service level for service operation.

The purpose of this paper is to provide an effective framework best suited for improving resilience capability to overcome the challenges from disruptive events faced by service organisations. With such research focus, the proposed framework can be one of the first studies that addressed the organisational resilience for service organisations in a coherent manner. Indeed, the proposed approach enables and facilitates the resilience of service organisations in today's turbulent business environment. The three levels of the framework help organisations to monitor and deal with different service components such as service proposal, service creation and service operation.

Concerning the implication for practice, service organisations can adapt the framework to determine the key concepts and to design their resilience process. The paper demonstrates the adaptation of the framework for cultural organisations in the domain of performing art. For the time being, an action-research project is currently carried out in selected cultural organisations to explore the different types of disruptive events, to identify relevant decisions, and to develop a dashboard for supporting those decisions.

Concerning the implications for research, the authors are currently working on developing a decision support system to help organisations to monitor and make the right decision at the right time for overcoming different disruptive events. Moreover, a resilience diagnostic system for analysing the resilience capacities of a service organisation and proposing relevant recommendations can be an interesting research direction. In the future, the framework can be enhanced to support collaborative business services and to design inter-organisational systems [45] for promoting inter-organisational resilience.

\section{References}

1. K. Burnard, R. Bhamra, Organisational resilience: development of a conceptual framework for organisational responses, International Journal of Production Research 49(18), 55815599 (2011)

2. A. Paraskevas, Crisis management or crisis response system?: A complexity science approach to organisational crises, Management Decision 44(7): 892-907 (2006)

3. J. L. Miller, C. W. Craighead, K. R. Karwan, Service recovery: a framework and empirical investigation, Journal of Operations Management 18(4): 387-400 (2000)

4. A. Annarelli, C. Battistella, F. Nonino, A Framework to Evaluate the Effects of Organisational Resilience on Service Quality, Sustainability 12(3): 958 (2020)

5. T. Le Dinh, T. T. Pham Thi, Information-driven framework for collaborative business service modelling, International Journal of Service Science, Management, Engineering, and Technology (IJSSMET) 3(1): 1-18 (2012)

6. S. Tengblad, A resource-based model of organisational resilience. In The Resilience Framework (pp. 39-54), Springer (2018)

7. J. Tasic, S. Amir, J. Tan, M. Khader, M., A multilevel framework to enhance organisational resilience, Journal of Risk Research 23(6): 713-738 (2020) 
8. S. Duchek, S. Raetze, I. Scheuch, The role of diversity in organisational resilience: a theoretical framework, Business research 13(2): 387-423 (2020)

9. S. McManus, E. Seville, J. Vargo, D. Brunsdon, Facilitated process for improving organisational resilience, Natural Hazards Review 9(2), 81-90 (2008)

10. R. Sanchis, L. Canetta, R. Poler, A Conceptual Reference Framework for Enterprise Resilience Enhancement, Sustainability 12(4): 1464 (2020)

11. T. Le Dinh, T. T. Pham Thi, Collaborative Business Service Modelling in KnowledgeIntensive Enterprises, International Journal of Innovation in the Digital Economy (IJIDE) 7(4): 1-22 (2016)

12. T. Le Dinh, Thang, M. Leonard, A conceptual framework for modelling service value creation networks, in Proceedings of 2009 International Conference on Network-Based Information Systems, IEEE, (2009)

13. R. F. Lusch, S. L. Vargo, G. Wessels, Towards a conceptual foundation for service science: Contributions from service-dominant logic, IBM Systems Journal 47(1): 5-14 (2008)

14. J. Spohrer, P.P. Maglio, J. Bailey, D. Gruhl, Steps Towards a Science of Service Systems, IEEE Computer 40(1): 71-77 (2007)

15. S. L. Vargo, R. F. Lusch, Evolving to a New Dominant Logic for Marketing, Journal of Marketing 68(1): 1-17 (2004)

16. S. T. March, G. F. Smith, Design and natural science research on information technology, Decision Support Systems 15(4): 251-266 (1995)

17. S. Alter, Metamodel for service analysis and design based on an operational view of service and service systems, Service Science 4(3): 218-235 (2012)

18. J. Rumbaugh, I. Jacobson, G. Booch, The Unified Modeling Language Reference Manual, Addison Wesley Longman (1999)

19. J. L. Peterson, Petri nets, ACM Computing Surveys (CSUR) 9(3): 223-252 (1977)

20. M. Léonard, T.T Pham Thi, Information System integration with the static and dynamic aspects, Advances in Multimedia and Databases for the New Century 10: 19-25 (1999)

21. Statistics Canada, Domains in the Canadian Framework for Culture Statistics, https://www150.statcan.gc.ca/n1/pub/13-607-x/2016001/1248-eng.htm (2021)

22. M. Podestà, G. Richards, Creating knowledge spillovers through knowledge-based festivals: the case of Mantua, Italy, Journal of Policy Research in Tourism, Leisure and Events 10(1): 1-16 (2018)

23. G. Richards, Cultural tourism: A review of recent research and trends, Journal of Hospitality and Tourism Management 36: 12-21 (2018)

24. D. Desai, Imaging difference: The politics of representation in multicultural art education, Studies in Art Education 41(2): 114-129 (2000)

25. J. Hill, Travelling objects: the Welcome collection in Los Angeles, London and beyond, Cultural Geographies 13(3): p. 340-366 (2006)

26. S. Botti, What role for marketing in the arts? An analysis of arts consumption and artistic value, International Journal of Arts Management 2(3): 14-27 (1999)

27. P. Butler, By popular demand: marketing the arts, Journal of Marketing Management 16(4): 343-364 (2000)

28. F. Colbert, F., Entrepreneurship and leadership in marketing the arts, International Journal Of Arts Management 6(1): 30-29 (2003) 
29. F. Colbert, The arts sector: A marketing definition, Psychology \& Marketing 31(8): 563565 (2014)

30. J. Ruiz, F. Colbert, A. Hinna, Arts and culture management, in Academila Revista Latinoamericana de Administración (2017)

31. R. Song et al., When marketing strategy meets culture: the role of culture in product evaluations, Journal of the Academy of Marketing Science 46(3): 384-402 (2018)

32. M. Boorsma, A strategic logic for arts marketing: Integrating customer value and artistic objectives, International journal of cultural policy 12(1): 73-92 (2006)

33. I. Fillis, The evolution and development of arts marketing research, Arts Marketing: An International Journal 1(1): 11-25 (2011)

34. P. Frow et al., Managing co-creation design: A strategic approach to innovation, British Journal of Management 26(3): 463-483 (2015)

35. K. Verleye, The co-creation experience from the customer perspective: its measurement and determinants, Journal of Service Management 26(2): 321-342 (2015)

36. S. McManus et al., Facilitated process for improving organisational resilience, Natural Hazards Review 9(2): 81-90 (2008)

37. S. Amir, V. Kant, Sociotechnical resilience: A preliminary concept, Risk Analysis 38(1): 8-16 (2018)

38. T. R. Rao et al., The big data system, components, tools, and technologies: a survey, Knowledge Information Systems Management: 1-81 (2018)

39. P. Zerbino et al., Big Data-enabled customer relationship management: A holistic approach, Information Processing \& Management 54(5): 818-846 (2018)

40. J. Bundy et al., Crises and crisis management: Integration, interpretation, and research development, Journal of Management 43(6): 1661-1692 (2017)

41. D.L. Yohn, 6 Ways to Build a Customer-Centric Culture, Havard Business Review (2018)

42. B. Tabrizi et al., Digital Transformation Is Not About Technology, Harvard Business Review (2019)

43. Gorton, C., Building digital leadership and resilience in the UK's Cultural sector (2016)

44. UNESCO, Policy guide for a resilient creative sector (2020)

45. T. Le Dinh, A. V. Nguyen-Ngoc. A conceptual framework for designing service-oriented inter-organisational information systems, in Proceedings of the 2010 Symposium on Information and Communication Technology (2010) 